\title{
TIPIFICAÇÕES E CULTURA VIVIDA NA SÉRIE ESPECIAL DO JORNAL NACIONAL COM OS JOGADORES DA SELEÇÃO BRASILEIRA
}

\author{
LAUREN SANTOS STEFFEN \\ UNIVERSIDADE FEDERAL DE SANTA MARIA \\ SANTA MARIA, RIO GRANDE DO SUL, BRASIL \\ E-MAIL: LAUREN.SSTEFFEN@GMAIL.COM
}

HTTP://DX.DOI.ORG/10.5902/2316882X25684 
TIPIFICAÇÕES E CULTURA VIVIDA NA SÉRIE ESPECIAL DO JORNAL NACIONAL COM OS JOGADORES DA SELEÇÃO BRASILEIRA

Resumo: A pesquisa relaciona as tipificações dos jogadores de futebol, construídas pela série especial no Jornal Nacional, e os elementos da cultura vivida. Como metodologia, apresenta uma proposta de análise cultural-midiática do telejornalismo esportivo, com base nos Estudos Culturais e na análise textual. Resultaram três tipificações de jogadores representadas na série: o tipo pobre, o tipo graduado e o tipo rico.

Palavras-chave: Estudos Culturais; tipificação; cultura vivida; telejornalismo esportivo.

TIPIFICACIONES Y CULTURA VIVIDA EN LA SERIE ESPECIAL DE JORNAL NACIONAL CON LOS JUGADORES DE LA SELECCIÓN BRASILEÑA

Resumen: La investigación asocia las tipificaciones de jugadores de fútbol, construidas por la serie especial de Jornal Nacional, y los elementos de la cultura vivida. La metodología propone un análisis cultural-mediático del periodismo de televisión deportivo, con base en los Estudios Culturales y el análisis textual. Los resultados mostraron tres tipificaciones de jugadores representados en la serie: el tipo pobre, el tipo graduado y el tipo rico.

Palabras clave: Estudios Culturales; tipificación; cultura vivida; periodismo de televisión deportivo.

TYPIFICATIONS AND LIVED CULTURE ON THE SPECIAL SERIES OF JORNAL NACIONAL WITH THE BRAZILIAN NATIONAL TEAM PLAYERS

Abstract: The research relates the typifications of soccer players, constructed by the special series of Jornal Nacional, and the elements of the lived culture. As methodology, it presents a proposal of a cultural-mediatic analysis of sports television journalism, based on the Cultural Studies and the textual analysis. There were three types of players represented on the series: the poor type, the graduated type and the rich type.

Keywords: Cultural Studies; typification; lived culture; sports television journalism.

Rev.Cad. Comun. Santa Maria, v.21, n.1, art 9, p.184 de 193, jan/abr.2017 


\section{INTRODUÇÃO}

Esta pesquisa se propõe a expandir a visão sobre o fenômeno do futebol na área do telejornalismo esportivo, compreendendo-o não só como um esporte, mas como parte da economia, da política, da sociedade e principalmente da mídia, que constrói narrativas hegemônicas, contribuindo para a disseminação da ideologia dominante. Desse modo, esta pesquisa visa contribuir no sentido de ampliar o nível de conhecimento sobre as tipificações construídas pelo telejornalismo esportivo em torno dos jogadores de futebol no Brasil, pontuando como esses sujeitos são representados e que possíveis impactos sociais estas construções podem implicar.

A partir da construção de uma proposta de análise cultural-midiática do telejornalismo esportivo com base nos Estudos Culturais e na análise textual, este trabalho busca analisar os elementos presentes no contexto de produção da série especial com os jogadores da Seleção Brasileira no Jornal Nacional, dando ênfase para a tensão existente entre as tipificações dos jogadores construídas pelo telejornalismo esportivo e a cultura vivida, que abrange o contexto social, político e econômico. Como resultados, apresentam-se os tipos construídos a partir da análise de três reportagens da série especial e seus modos de representação.

\section{DESENVOLVIMENTO}

\subsection{ESTUDOS CULTURAIS E TIPIFICAÇÃO}

Os Estudos Culturais são considerados uma perspectiva teórica que analisa as relações entre sociedade e práticas culturais. Segundo Escosteguy (2010), o eixo principal de pesquisa estava centrado nas relações entre a cultura contemporânea e a sociedade com enfoque nas instituições, formas e práticas culturais. Para a autora, o ponto de partida dos estudos recai sobre as estruturas sociais e o contexto histórico como elementos essenciais para compreender a ação dos meios massivos e o deslocamento da ideia elitista de cultura em direção a suas práticas cotidianas.

Em uma revolução do marxismo clássico, os Estudos Culturais passam a defender que a cultura não é um campo autônomo nem externamente determinado, mas um local de diferenças e lutas sociais. Para contrapor o materialismo econômico de Marx, Williams (1992) cunha o termo ma-

Rev.Cad. Comun. Santa Maria, v.21, n.1, art 9, p.185 de 193, jan/abr.2017 
terialismo cultural, a partir da qual as práticas culturais devem ser entendidas como práticas reais, elementos de um processo social material, com condições específicas. Williams (1992) coloca que a dominação em uma sociedade não se dá apenas a partir da propriedade e do poder. A cultura do vivido também exerce influência na nossa forma de pensar e sentir através de suas pressões e limites. O campo rompe, assim, com as concepções passivas e indiferenciadas de público (HALL, 2003). Neste trabalho, o conceito de cultura vivida terá como base o conceito de consciência prática desenvolvido por Williams (1979), que se relaciona com aquilo que está sendo realmente vivido, ou seja, as experiências sociais que estão sendo definidas e sentidas ativamente pelos sujeitos em determinado contexto.

O conceito de tipificação desenvolvido por Williams (1979) será utilizado para dar conta do conceito de representação, uma vez que o caráter típico se refere a uma figura específica que concentra e intensifica uma realidade muito mais geral. A tipificação não é a representação de leis, mas do processo dinâmico da realidade, que se expressa em um tipo particular. Trata-se, assim, de um exemplo representativo de uma classificação significativa. Além disso, o tipo diz respeito a uma experiência que busca se estabelecer à prova de crise por meio de ritos, apelando para narrativas míticas e para o inconsciente coletivo (WILLIAMS, 1979). Todo tipo é fruto de seu contexto, pois cristaliza o processo histórico em uma imagem dialética. $O$ objetivo da tipificação é sintetizar a complexidade do real em uma forma particular.

\subsection{FUTEBOL E TELEJORNALISMO ESPORTIVO}

O telejornalismo esportivo narra modos de existência através de sons e imagens que têm uma participação significativa na vida das pessoas, uma vez que pautam, orientam e interpelam o cotidiano dos telespectadores, participando da circulação e consolidação das representações ideológicas dominantes. As narrativas telejornalísticas atuam na construção simbólica das identidades, pois estas precisam ser representadas para serem reconhecidas. Certos elementos são constantemente reiterados nos telejornais para retratar a identidade brasileira, constituindo-se em um quadro de referência comum compartilhado pelos sujeitos do grupo. Um desses elementos é a superação, ideia que repetidamente é invo- 
cada para representar as histórias de vida dos jogadores de futebol na televisão.

Os jogadores de futebol são representados pelo telejornalismo através da característica do ídolo-herói, que transforma o universo do futebol em um terreno extremamente fértil para a produção de mitos e ritos relevantes para a comunidade. Dotados de talento e carisma, o que os singulariza e os diferencia dos demais, estes heróis são paradigmas dos anseios sociais e, através de suas trajetórias de vida, podemos perceber alguns traços que são frequentemente recorrentes e enfatizados (HELAL, 1998). Tais construções operam como lugar de reforço de estigmas, atuando para a permanência de estereótipos e preconceitos por meio de estratégias de redundância (SOARES, 2010). Nesse sentido, o telejornal segue o modelo que lhe interessa para manter a estrutura de poder e anula todos os que rompem ou tentam romper com o modelo social dominante.

\section{CONSIDERAÇÕES METODOLÓGICAS}

A proposta de análise cultural-midiática do telejornalismo esportivo (Figura 1) coloca em relação esferas que são interligadas e fundamentais para a compreensão do todo. A esfera do telejornalismo esportivo representa o lugar de construção das tipificações no futebol, através de modos de representação. A partir da série especial exibida no Jornal Nacional, mapearemos os tipos de jogadores construídos pelo discurso telejornalístico e seus possíveis impactos sociais. Através da metodologia de análise textual (CASETTI; CHIO, 1999), analisaremos três reportagens da série sobre as histórias de vida dos jogadores convocados para a Copa do Mundo de 2014, chegando a categorias que evidenciem as tipificações construídas pelo telejornal e seus modos de representação.

As dimensões da economia, sociedade e política compõem a cultura vivida que permeia as representações telejornalísticas. Assim, buscando as relações e tensões do contexto com as tipificações construídas pelo telejornalismo, buscamos evidenciar que, mais do que formas e imagens subjetivas, elas se constituem como práticas sociais, que atuam na atualização, reforço e silenciamento de sentidos, os quais, por sua vez, participam da construção das identidades, da cristalização de preconceitos e da propagação de estereótipos. O telejornalismo esportivo aparece no

Rev.Cad. Comun. Santa Maria, v.21, n.1, art 9, p.187 de 193, jan/abr.2017 
centro como fenômeno norteador da análise cultural-midiática empreendida, cuja compreensão depende da articulação de todas as esferas, as quais possibilitam contextualizar e complexificar as tipificações do esporte na sociedade contemporânea.

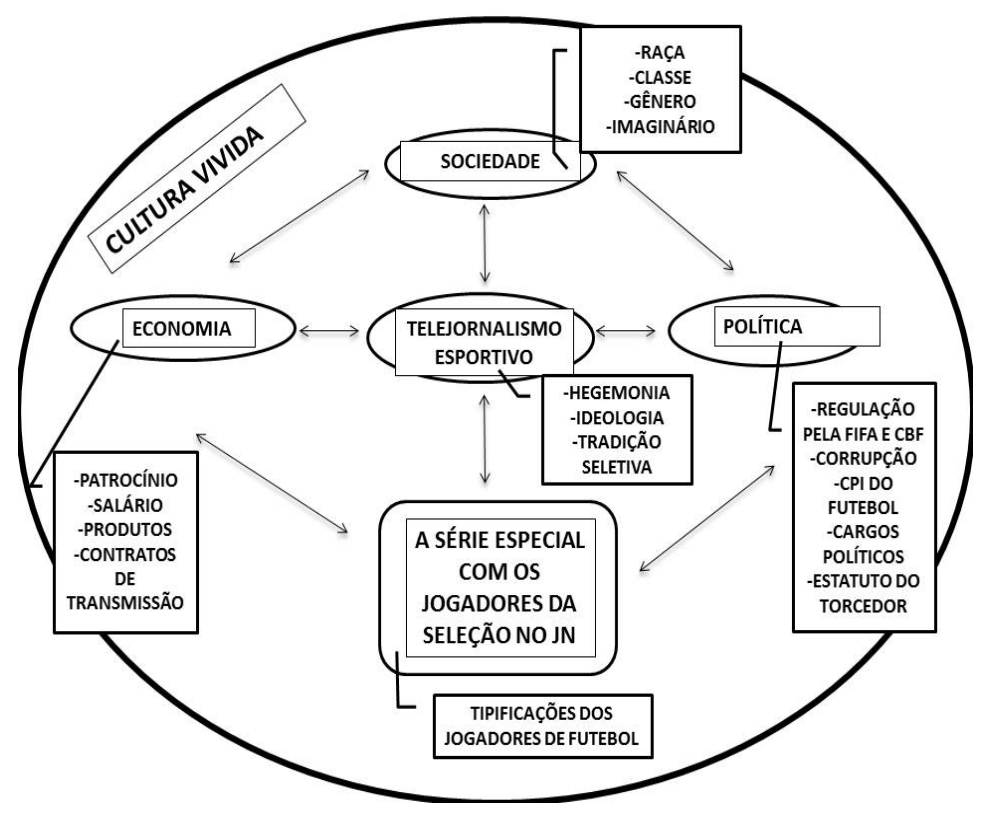

Figura: Análise cultural-midiática do telejornalismo esportivo.

Fonte: Elaborado pela autora.

\section{RESULTADOS}

Através da metodologia de análise textual, observamos a existência de uma tipificação hegemônica enfatizada pela série, representativa da maioria dos jogadores, a qual denominaremos como tipo pobre. Daniel Alves, o qual se classifica nessa tipificação, é descrito através de uma personalidade carismática, alegre e batalhadora. São destacados os obstáculos que esse jogador teve que ultrapassar para conquistar o sucesso na profissão, como suas origens humildes no sertão nordestino, a saudade da família e dos amigos, as condições precárias dos primeiros centros de treinamento. Todas essas adversidades precisaram ser necessariamente vencidas, com muita força de vontade, a fim de se tornar um jogador consagrado na profissão, o que é percebido, na série, através da ascensão econômica do atleta e, consequentemente, de sua família.

A consagração desses jogadores é representada através da sua ascensão econômica; a miserabilidade não deixa de ser narrada, mas é apenas representada para marcar o ponto inicial, a partir do qual todos Rev.Cad. Comun. Santa Maria, v.21, n.1, art 9, p.188 de 193, jan/abr.2017 
deveriam necessariamente querer sair. $O$ tipo pobre relembra as suas origens humildes e demonstra gratidão às pessoas que o ajudaram, deixando claro que é preciso ir em busca de uma vida melhor e incentivar os jovens a irem atrás de seus objetivos, como se bastasse querer ser jogador para obter sucesso. Assim, parece que a situação econômica é responsabilidade exclusiva de cada um, o que demonstra, em uma equação simplista, que, se o indivíduo não conquistou seu espaço no esporte, é porque não lutou o suficiente pelo seu sonho.

Os raros casos de jogadores que vêm de famílias com uma situação financeira mais confortável, como é o caso de Maxwell, são mencionados de forma atenuada na série a fim de que a informação passe despercebida do público e de que a ficção construída em torno das histórias de vida dos jogadores se mantenha de acordo com o padrão estabelecido. Parece que o fato de existirem jogadores com situação econômica mais favorável no esporte ameaça a ideia padronizada de que todos os jogadores de futebol saíram da sua situação inicial de miséria e conquistaram a ascensão econômica, o que abalaria a tentativa da série de reforçar a associação entre ser jogador de futebol e conquistar um status mais favorável na sociedade, fator que alimenta o sonho de milhares de crianças no país e estimula a estratificação social, reforçando a divisão e o preconceito entre as classes. O tipo rico apresenta um potencial de se constituir como uma força contra-hegemônica, resistindo à construção padronizada do tipo pobre.

A questão da escolaridade atua na construção do tipo graduado, representada pelo caso único do goleiro Victor na série. $O$ goleiro se superou ao conseguir se formar em um curso de ensino superior, estudando durante as concentrações e se dividindo entre a sala de aula e o campo de futebol. Victor é um caso raro no futebol, o que demonstra o seu esforço para concluir a faculdade e para buscar mais conhecimento e sua consciência ao pensar em um plano secundário diante de uma profissão tão instável quanto a de jogador. Outros casos de jogadores que concluíram o ensino superior são Sócrates (década de 1980) e Tostão (final da década de 1960), graduados em Medicina, e César Sampaio (final da década de 1990), graduado em Administração. A partir de uma representação sutil dessas exceções no esporte, a série reforça os lugares reservados a cada classe na sociedade, cabendo aos mais favorecidos economicamente conquistar o diploma de ensino superior em profissões liberais

Rev.Cad. Comun. Santa Maria, v.21, n.1, art 9, p.189 de 193, jan/abr.2017 
prestigiadas, e deixando para as classes menos abastadas a obrigação de se conformar com sua situação econômica, exercendo funções que não exijam instrução formal.

Na tabela a seguir, evidenciamos os tipos hegemônico e contra-hegemônico construídos na série a partir da análise das histórias de vida de Maxwell, Victor e Daniel Alves. Além disso, demonstramos seus diferentes modos de representação, regidos pelos valores culturais vivenciados no presente, como forma de sintetizar o que foi exposto.

\begin{tabular}{|c|c|c|}
\hline TIPIFICAÇÃO & $\begin{array}{c}\text { MODO DE } \\
\text { REPRESENTAÇÃO }\end{array}$ & $\begin{array}{c}\text { EXEMPLO } \\
\text { ANALISADO }\end{array}$ \\
\hline Hegemônica: POBRE & Destaque & Daniel Alves \\
\hline Contra-hegemônica: RICO & Atenuação & Maxwell \\
\hline Contra-hegemônica: GRADUADO & Concessão & Victor \\
\hline
\end{tabular}

Tabela - Tipos de Jogadores de Futebol Representados na Série

\section{CONCLUSÕES}

É fundamental ressaltar que o fato da série de reportagens colocar os jogadores de futebol como protagonistas, a partir de suas histórias de vida, não significa que eles estão ganhando um espaço de fala. Suas histórias de vida são contadas através dos critérios editoriais da emissora, das estratégias narrativas adotadas pelo repórter, dos trechos das falas selecionados como merecedores de atenção, dos enquadramentos da câmera, dos destaques das trilhas sonoras, da interpretação de alguns fatos de sua vida tidos como relevantes pelo telejornal. Nesse sentido, os jogadores são apenas personagens passivos, conduzidos pelos interesses do telejornal, usados para propagar a ideologia dominante defendida pela emissora.

Ao buscar evidenciar o protagonismo dos jogadores de futebol, colocando-os como personagens principais da série, a emissora e o telejornal cumprem apenas com uma tarefa mercadológica, na tentativa de ganhar audiência e gerar identificação através de uma representação ilusória e homogênea desses atletas. Por outro lado, esse falso protago-

Rev.Cad. Comun. Santa Maria, v.21, n.1, art 9, p.190 de 193, jan/abr.2017 
nismo encobre inúmeras situações problemáticas, transmitindo a ideia de que se valoriza e representa todos os jogadores de futebol, sem levar em conta a diversidade e pluralidade de suas histórias de vida.

É preciso ultrapassar o discurso repetitivo e estereotipado, desconstruir preconceitos, avançar para debates mais complexos e dar abertura para reflexões políticas, sociais e econômicas em torno do esporte a fim de podermos cumprir o papel social do jornalismo com o interesse público e mostrar o potencial do esporte como catalisador social, promotor da cidadania e construtor da criticidade. Quando todos tiverem o mesmo ponto de partida e as mesmas possibilidades, poderemos individualizar o sucesso de algumas histórias de vida e relacioná-las ao esforço pessoal e ao talento de cada um. No entanto, enquanto ainda tivermos que conviver com a desigualdade social, não poderemos falar em sucesso individual de alguns, mas em fracasso coletivo de todos nós, enquanto sociedade. 


\section{REFERÊNCIAS}

CASETTI, Francesco; CHIO, Frederico di. Análisis de la televisión: instrumentos, métodos y práticas de investigación. Paidós: Barcelona, 1999.

ESCOSTEGUY, Ana Carolina. Estudos Culturais: uma introdução. In: SILVA, Tomaz Tadeu da. (Org.). O que é, afinal, Estudos Culturais?. Belo Horizonte: Autêntica, 2010, p. 135-166.

HALL, Stuart. Codificação/Decodificação. In: HALL, Stuart; SOVIK, Liv (Orgs.). Da diáspora: identidades e mediações culturais. Belo Horizonte: UFMG; Brasília: UNESCO, 2003, p.387-404.

HELAL, Ronaldo. Mídia, construção da derrota e o mito do herói. Motus Corporis (UGF), Universidade Gama Filho, Rio de Janeiro, v.5, n.2, 1998.

SOARES, Rosana de Lima. Estigmas sociais em narrativas audiovisuais: entre consolidação e transgressão. Disponível em: http://compos.com.puc-rio.br/media/gt5_rosana_de_lima_soares.pdf. Acessado em 04 de abril de 2016.

WILLIAMS, Raymond. Marxismo e literatura. Rio de Janeiro, Zahar, 1979.

. Cultura. Rio de Janeiro: Paz e Terra, 1992. 


\section{Lauren Santos Steffen}

Doutoranda em Estudos Linguísticos na Universidade Federal de Santa Maria. Mestre em Comunicação Midiática - Linha Mídia e Identidades Contemporâneas pela Universidade Federal de Santa Maria. Graduada em Letras - Português/Inglês pela PUCRS e em Jornalismo pela UFRGS.

Dissertação defendida em 24/08/16 e orientada pelo professor Doutor Flavi Ferreira Lisboa Filho.

RECEBIDO EM: 24/01/2017

ACEITO EM: 23/03/2017 